\title{
Growth of centimeter scale carbon wires using in-liquid AC arc discharge
}

\author{
Krzysztof Jankowski ${ }^{1}$ (1) $\cdot$ Agnes Ostafin ${ }^{2,3,4} \cdot$ Mikołaj Tomasik $^{1} \cdot$ Tebello Nyokong $^{5} \cdot$ Jonathan Britton $^{5}$
}

Received: 6 February 2020 / Accepted: 6 April 2020 / Published online: 12 May 2020

(c) The Author(s) 2020 OPEN

\begin{abstract}
A novel observation of the formation of carbon wire in a carbon-based liquid solvent, using in liquid high voltage $\mathrm{AC}$ arc discharge is described. The authors describe the observed phenomenon, technical equipment needed to achieve the effect and preliminary qualitative results of obtained material. The wire consisted of well packed layers of carbon elements. The arc-discharge method is a simple, low cost method for the production of three dimensional carbon structures. A further research is needed to get a thorough understanding of the phenomenon.
\end{abstract}

Keywords Carbon wires · High voltage · AC arc discharge $\cdot$ Carbon structure · Graphite electrodes · Graphite · Organic chemistry · Canola oil

\section{Introduction}

Graphite is a naturally-occurring form of crystalline carbon [1]. It is extremely soft, cleaves with very light pressure, and has a very low specific gravity. In contrast, it is extremely resistant to heat and nearly inert in contact with almost any other material [2-4]. These extreme properties give it a wide range of uses in metallurgy and manufacturing [5-7]. The methods for obtaining carbon materials are many and most important of them include: arc discharge [8], laser ablation [9], plasma torch [10], chemical vapor deposition (CVD) [11, 12], liquid electrolysis method [13], epitaxy [14]. There are many works about production of carbon nanostructures by in-liquid plasma or arc discharge method [15-23], However, there are no works about synthesis of centimeter scale carbon wires. The problem of present technologies is their inability to obtain carbon materials in 3D form.

In this study we report a new phenomenon: the manufacture of stable carbon wire in a carbon-based liquid solvent, using in liquid high voltage $A C$ arc discharge. To achieve this effect, carbon electrodes are immersed in canola oil, and voltage applied using a simple power supply based on a autotransformer and microwave oven transformer (MOT). This solution allows to obtain a stable AC arc discharge between the electrodes. The electrodes were slowly moved away from each other using a stepper motor. Over time, a wire of carbon material appeared between the electrodes, and its length increased commensurate with the speed at which the electrodes moved away from each other.

Electronic supplementary material The online version of this article (https://doi.org/10.1007/s42452-020-2881-2) contains supplementary material, which is available to authorized users.

Krzysztof Jankowski, kjankowski@ajp.edu.pl | 'Department of Technology, The Jacob of Paradies University, ul. Chopina 52, 66-400 Gorzow Wielkopolski, Poland. '2 Departments of Chemical Engineering and Bioengineering, University of Utah, Salt Lake City, UT, USA. ${ }^{3}$ Nanolnstitute, University of Utah, Salt Lake City, UT 84054, USA. ${ }^{4}$ Nanoshell Research Institute, Salt Lake City, UT 84105 , USA. ${ }^{5}$ Department of Chemistry, Centre for Nanotechnology Innovation, Rhodes University, P.O. Box 94, Grahamstown 6139, South Africa. 


\section{Materials and methods}

\subsection{Materials}

Canola Oil (food grade) was purchased at the local farmers market. Graphite rods (99.9\% C) used as electrodes were purchased from Onyxmet, Sielska 10A 10-802 Olsztyn - Poland.

\subsection{Methods}

Carbon wires were produced at ambient conditions in canola oil, by mounting two moveable carbon electrodes in the device shown in Fig. 1 (Panel A). To start the process of carbon wire formation two electrodes were immersed in the canola oil, and the distance between the two electrodes was reduced until a stable $A C$ arc discharge was generated. The process was performed in air, at room temperature, without use of a gas/liquid injector. The speed of stepper motor was 1 step/10 s (Nema 17 stepper motor was used-200 steps per revolution, 1.8 degrees) and the time for obtaining a wire approximately $1 \mathrm{~cm}$ in length was $5 \mathrm{~min}$. The process was performed in air, at room temperature, without use of a gas/liquid injector (i.e. no additional reactive gases or liquids were used). The electrical system indicated in Fig. 1 (Panel B) consisted of an autotransformer (smooth regulation over the voltage range 0-230 V) plugged to a high voltage microwave oven transformer: Microwave Oven Transformer (such a transformer powers the magnetron in microwave ovens). This circuit allows the generation of voltages in the range of $0-2.1 \mathrm{kV}$. The resistance of the graphite rod used was $0.0643 \mathrm{Ohm}$,

A

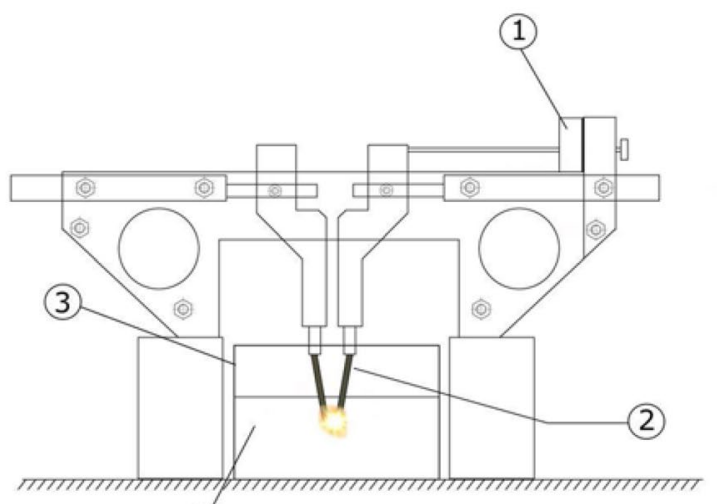

(4)

Fig. 1 Diagram of experimental set-up. a Submerging arc discharge reactor: 1-stepper motor, 2-graphite electrodes, 3-beaker, 4oil solvent. b General electric scheme: the autotransformer is con- measured using an LCR Meter Model 880-BK Precision (rod length $100 \mathrm{~mm}$ and diameter $8 \mathrm{~mm}$ ).

\subsection{Analysis}

The voltage value was measured using high voltage differential probe (DP-100, Pintek Electronics Co., Ltd.), the current measurement was made using a current probe (PA-677, Pintek Electronics Co., Ltd.) and data was stored in a digital oscilloscope (MSO1074Z, Rigol).

The morphology of the carbon wire was examined by scanning electron microscopy (SEM) using a scanning electron microscope/EDS system (Quanta 600F-FEI, Oregon, USA) located at NanoFab Center at the University of Utah. Transmission electron microscope imaging was performed using a JEOL JEM 2800.

Additional measurements were obtained using X-ray powder diffraction were recorded on a Bruker D8 Discover equipped with a Lynx Eye Detector, using $\mathrm{Cu}$-Ka radiation $(\lambda=1.5405 \mathrm{~A}$, nickel filter). Data were collected in the range from 2 theta $=10^{\circ}$ to $100^{\circ}$, scanning at $1.5^{\circ} \mathrm{min}^{-1}$ with a filter time-constant of $0.38 \mathrm{~s}$ per step and a slit width of $6.0 \mathrm{~mm}$. Samples were placed on a silicon wafer slide. The X-ray diffraction data were treated using the Eva (evaluation curve fitting) software. Baseline correction was performed on each diffraction pattern by subtracting a spline function fitted to the curved background.

Raman spectra were obtained from a Bruker Vertex 70-Ram II Raman spectrometer fitted with a $1064 \mathrm{~nm}$ $\mathrm{Nd}$ : YAG laser and a liquid nitrogen cooled germanium detector.

B

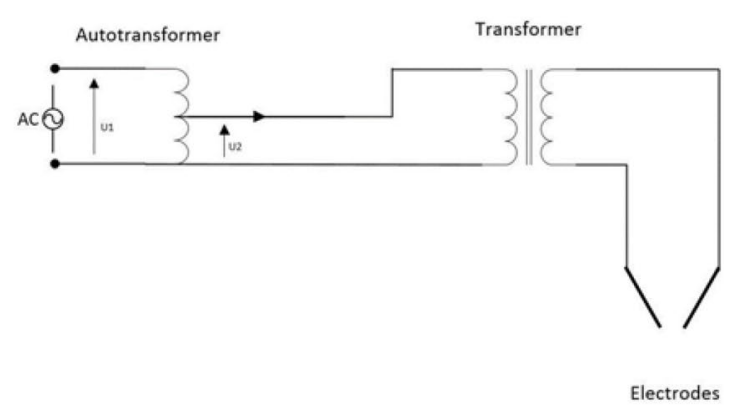

nected directly to high voltage transformer. This connection guarantee setting the voltages in the range between 0 and $2000 \mathrm{~V} \mathrm{AC}$ 


\section{Results and discussion}

Figure 2 shows the current-voltage waveforms of the AC arc discharge. The open circuit voltage before beginning the process was $1.2 \mathrm{kV}$ (i.e. measured on the secondary winding MOT). During the process the maximum voltage was $350 \mathrm{~V}$, and maximum current was $0.8 \mathrm{~A}$. When measuring the current-voltage characteristics for the state of the electric arc discharge, the classic process was observed. Three characteristic phenomena accompanying arcing process can be observed: arc ignition, maintenance, and extinguishing. The process of carbon wire growth begins with a discharge and continues until the first structures build up on the graphite rods. The electrode feed speed of

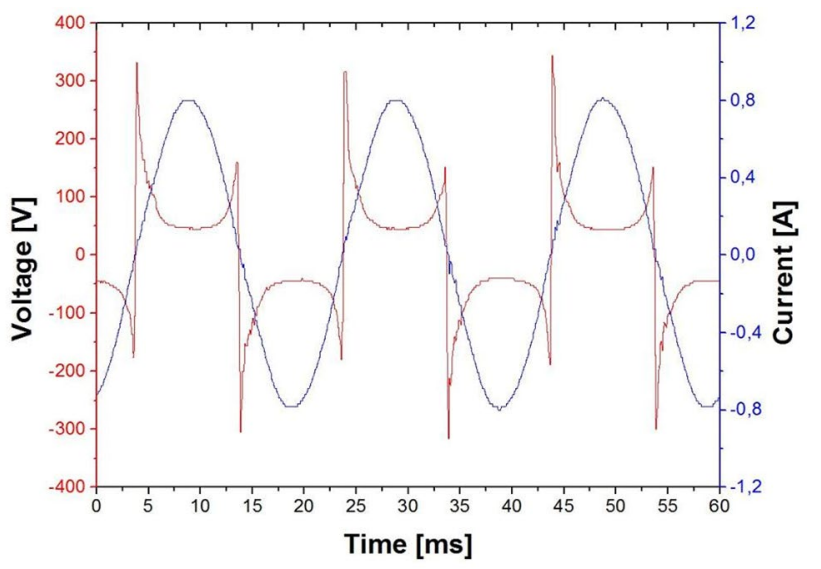

Fig. 2 Current-voltage characteristics the stepper motor (1step/10 s) allows the carbon structure to continue to grow in length while maintaining relatively constant current-voltage conditions.

If the stepper motor is not used to mechanically move the electrodes apart it was observed that the electric arc lost its parameters (it extinguished) after the growth of structures on the electrode surface. When the separation of the graphite electrodes from each other returns to its original value (approx. $1.2 \mathrm{~mm}$ ) the carbon structures grow further. Arc quenching may be related to the impending short circuit of the electrodes (because carbon nanostructures grow on both sides of the electrodes and approach each other). The maximum length of carbon wire obtained was using a $250 \mathrm{ml}$ glass vessel, a wire $25 \mathrm{~mm}$ in length and $1 \mathrm{~mm}$ in diameter was obtained.

Figure 3 shows a photograph of carbon material growing between the two electrodes. A series of SEM images of this wire are shown in Fig. 4. Panel A shows the overall morphology of the wire. The walls are smooth and wire diameter is relatively constant. Small perturbations in the wire diameter are the result of the discontinuous movement of the electrodes driven by the stepper motor. This could be eliminated using a geardriven motorized system in which the electrodes move slowly but continuously away from each other as the wires grow. Panels $B, C, D$ show the surface of the wire in increasing detail revealing well packed islands similar in character to Hummers' method grown of graphene oxide (GO) [23] with asperities clearly shown in Panels E, F. Figure 5 shows transmission electron micrograph images on a cross section of a typical wire. The well-packed pattern of carbon atoms in the interior of the wire, seen in
Fig. 3 Photograph of growing carbon wire. a Beginning of the process (initiation of an electric arc discharge); b front view; c obtained carbon wire materials; $\mathbf{d}$ steps of the process
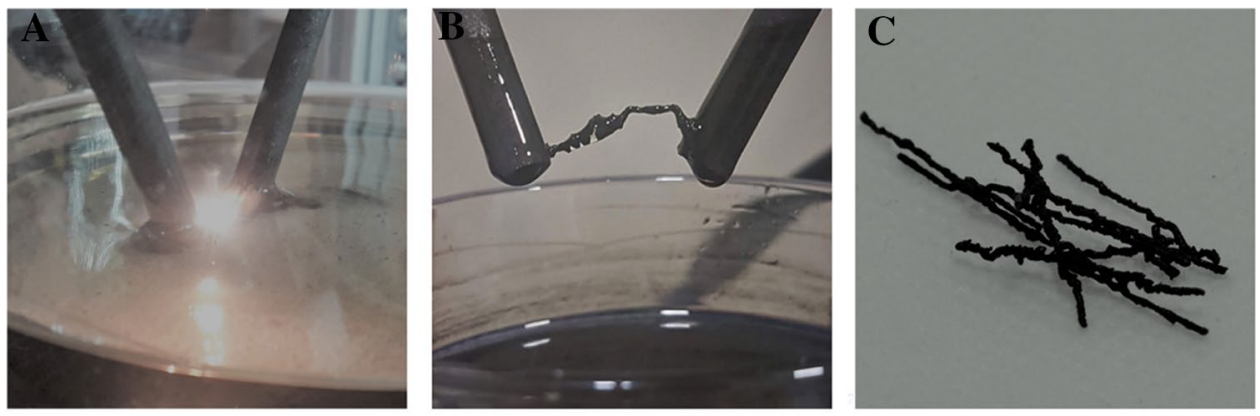

D

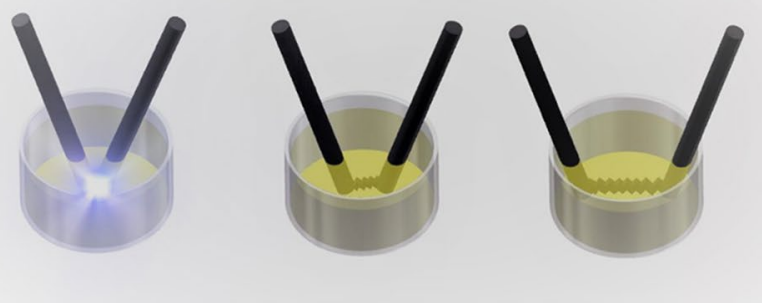

SN Applied Sciences a SPRINGER NatURE journal 

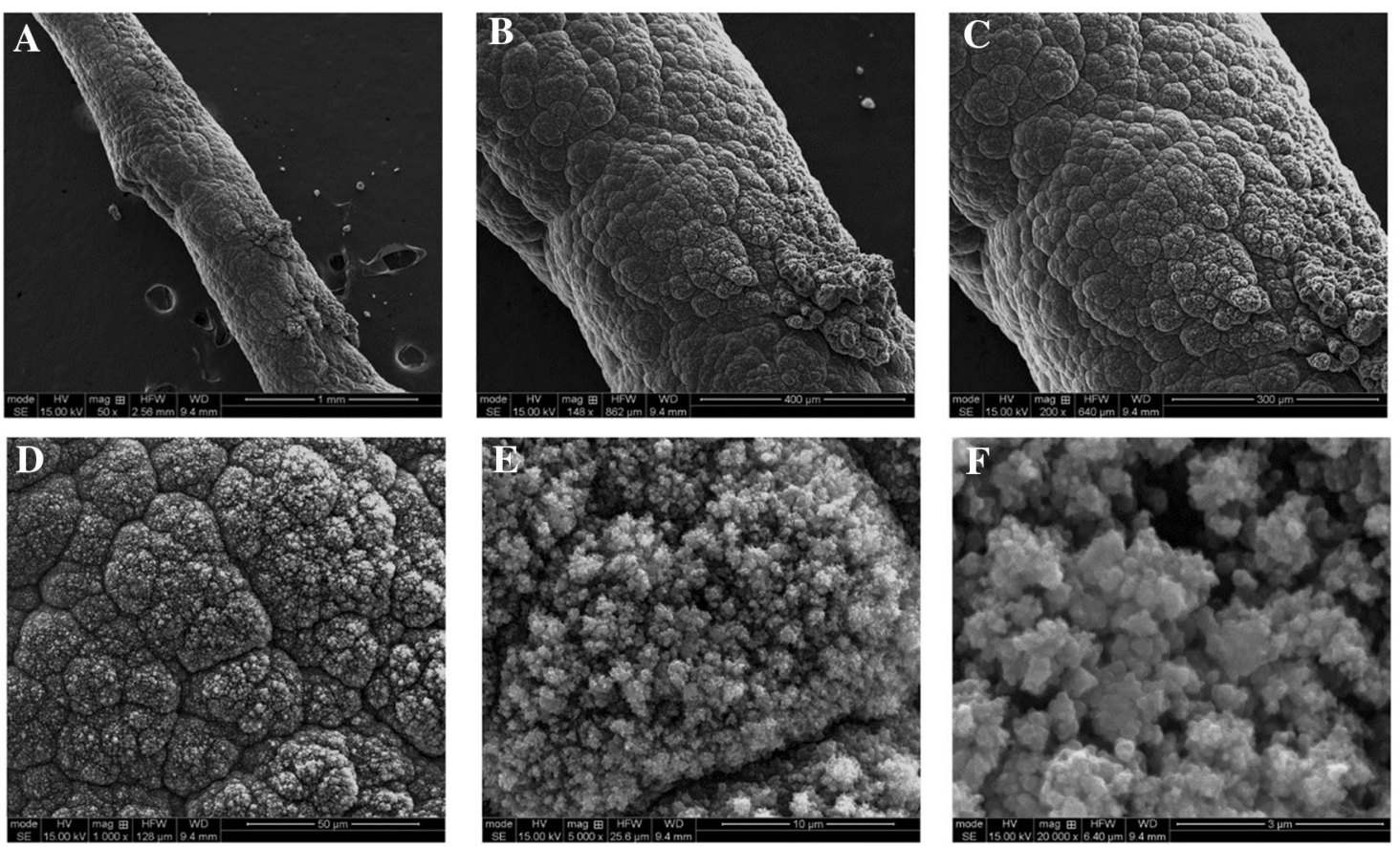

Fig. 4 SEM images/EDX analyses of carbon nanowire
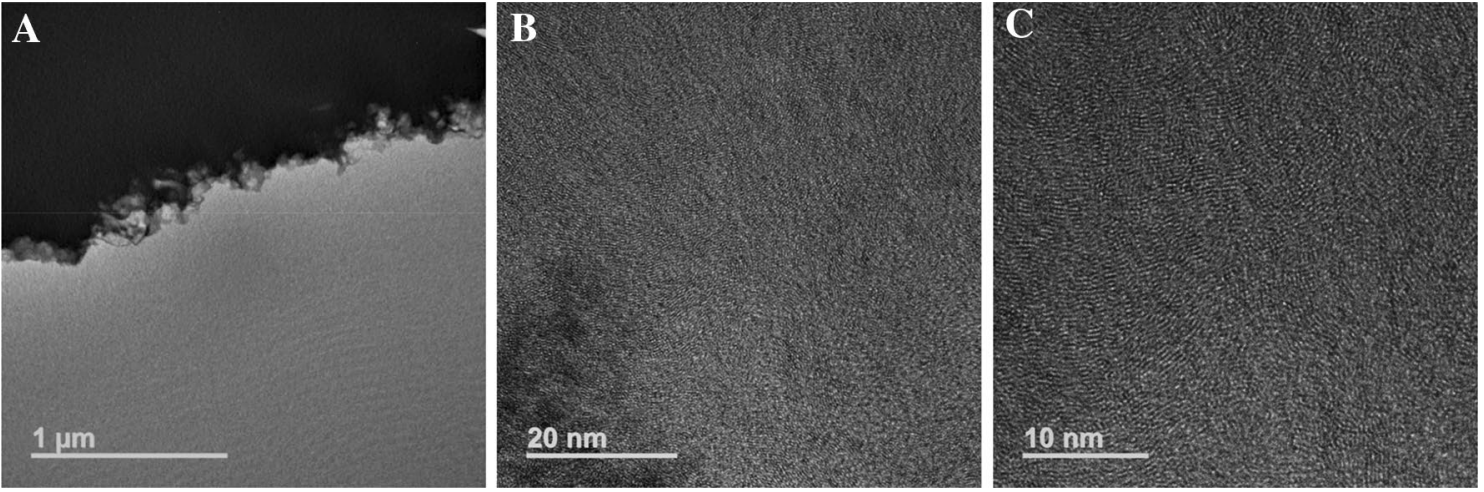

Fig. 5 Transmission electron microscope images of wire cross section

Panel B, suggests a large amount of disordered layering inside the wire. Taken together, these results suggests a mixture of disordered graphite. A high resolution TEM image of a cross section of the wire is shown in Fig. 5, Panel A. The well-packed pattern of carbon atoms in the interior of the wire, seen in Panel B and C, suggests a large amount of disordered graphite layering inside the wire. Combined with the results of other analyses, which are sensitive probes of material surfaces, it would appear that the wire produced in the liquid arc discharge process grows in the liquid as disordered layers of graphite and suggest occurrence graphene oxide (GO), but higher resolution of TEM analyses is necessary to confirm that thesis.
The XRD spectrum (Fig. 6) also shows evidence for both graphite and probably GO structure. The most intense diffraction peaks were recorded at the angle (20): $16.1^{\circ}$ (can suggested $\mathrm{C} 001$ peak found in graphene oxide (GO). The position of this peak is shifted. It usually occurs in the range of $11^{\circ}-13^{\circ}$ but it is possible to shift the diffraction peaks when the graphene oxide has been treated by high temperatures [24]) and $78.2^{\circ}$ (hexagonal graphite $C(110)$ ).

The diffraction peaks were also registered the angle

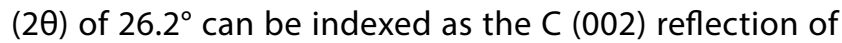
the hexagonal graphite structure. The other characteristic diffraction peaks of graphite at $2 \theta$ were observed of about $43^{\circ}, 53^{\circ}$ are associated with $C(100), C(004)$ respectively. Other diffraction peaks can also be noted $\left(63.0^{\circ}\right.$ and $\left.93.9^{\circ}\right)$. 


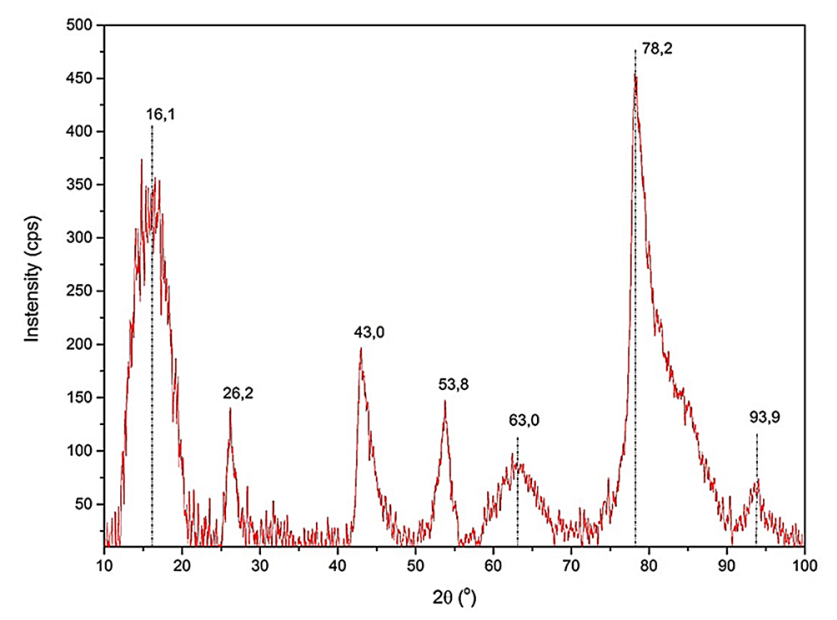

Fig. 6 XRD spectrum of the carbon wire material

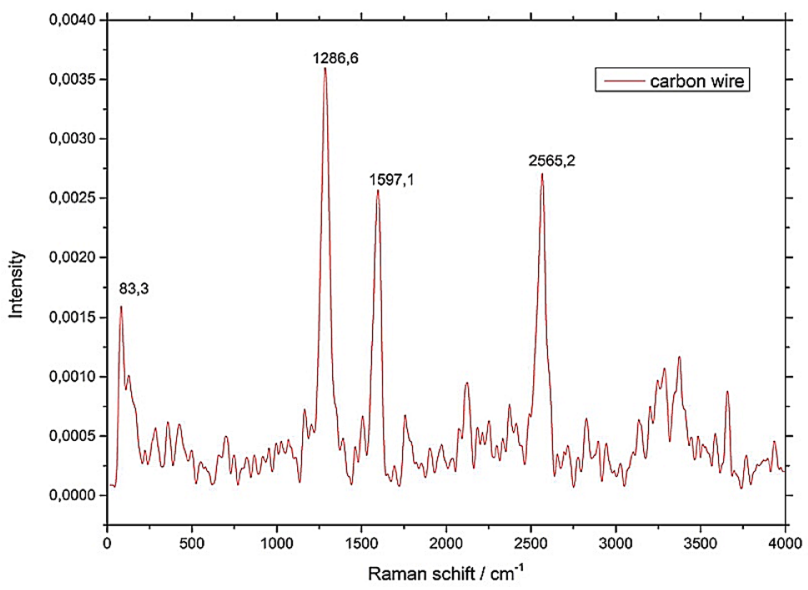

Fig. 7 Raman spectrum (1064 nm excitation wavelength) of carbon wire

This distribution of diffraction peaks may suggest occurrence of various carbon structures such as graphite and graphene oxide (GO).

The Raman spectrum (1064 nm excitation wavelength) of carbon wire (Fig. 7) reveals signatures: $1290 \mathrm{~cm}^{-1}$ D-band, $1597 \mathrm{~cm}^{-1} \mathrm{G} / \mathrm{D}^{\prime}$-bands and a $2565 \mathrm{~cm}^{-1}$ band reminiscent of the $\mathrm{G}^{\prime}$ and possibly the $2 \mathrm{D}$ band.

The formation of the graphene-based wire requires the presence of a carbon based fluid. In ultrapure water (18 MOhms), for example, arcing occurs, but no wire formation is observed. Rather, carbon atoms liberated from the electrodes form suspended particles which accumulate over time. In this example, the fluid was canola oil, with components: oleic acid, linoleic acid, alpha linoleic acid. These are largely linear molecules (C16-C18), with one or more carbon double bonds in the chain, capped with a carboxylic acid group. To form graphene from these molecules, among other things, it is necessary to liberate $\mathrm{CO}_{2}$ gas and to ionize at least some of the carbons in the lipophilic chain in order to form hexagonal structures.

The use of AC current allows the formation of carbon wire structures on both graphite electrodes. Since graphene is normally produced either by exfoliation or by two dimensional deposition there must exist conditions in the arc discharge that facilitate alignment of the molecular fragments to form a tightly packed structure as shown on Fig. 5. The high local temperatures, and large electron flux between the electrodes generates the needed ionization to allow the linear molecules to reform into hexagonal structures found in graphene. Most likely the high voltage between the electrodes can generate a significant degree of electrical polarization of the molecular fragments that assists in their alignment (although local magnetic fields may play a role). The start of alignment creates a sort of two dimensional template, that can add material from both above and below to form a three dimensional wire. As the strength of the electric flux lines diminishes the degree of polarization diminishes and the diameter of the formed wire reaches its maximal size. This would suggest that optimizing the shape of the electrodes and their contact area could be used to control the final size and shape of the wire. More work in this area is needed.

\section{Summary}

A three dimensional carbon wire material was produced in an ambient condition, arc discharge method in a carbonbased fluid. The wire consists of well packed layers of disordered graphite and probably graphene oxide (GO). The high voltage $A C$ arc-discharge method is a simple, low cost method for the production of three dimensional carbon structures. This article only presents the observed effect of creating carbon structures and the further work must be focus on a thorough explanation of the problem. The first step in this area should be to explain the relationship between parameters such as voltage and current and their impact on the carbon wire growth process. Temperature stabilization (maintaining a constant oil temperature) is also an important element. Also in further works mechanical properties of the obtained material (i.a. hardness) should be determined. A more elaborate control system could be employed to create more complicated structures.

Acknowledgements Special thanks to Paweł Uznanski from Centre of Molecular and Macromolecular Studies of Polish Academy of Sciences (Poland), Mr. Francis Chindeka from Rhodes University (South Africa), Mr. Szymon Caluch from The Jacob of Paradies University (Poland), Mr. Paweł Mazurek from The Jacob of Paradies University (Poland) the Nanoshell Research Institute (Salt Lake City, UT), and Paulo Perez and Brian van Devener from the University of Utah (USA). 
Funding This work was supported by the fund of Rector Scholarship of Jacob of Paradies University in Gorzow Wielkopolski and the department of Science and Technology, Republic of South Africa and National Research Foundation through DST/NRF South Africa Research Chairs Initiative for Professor of Medicinal Chemistry and Nanotechnology (Grant Number UID 62620) and Rhodes University.

\section{Compliance with ethical standards}

Conflict of interest The authors declare that they have no conflict of interest.

Open Access This article is licensed under a Creative Commons Attribution 4.0 International License, which permits use, sharing, adaptation, distribution and reproduction in any medium or format, as long as you give appropriate credit to the original author(s) and the source, provide a link to the Creative Commons licence, and indicate if changes were made. The images or other third party material in this article are included in the article's Creative Commons licence, unless indicated otherwise in a credit line to the material. If material is not included in the article's Creative Commons licence and your intended use is not permitted by statutory regulation or exceeds the permitted use, you will need to obtain permission directly from the copyright holder. To view a copy of this licence, visit http://creativecommons .org/licenses/by/4.0/.

\section{References}

1. Anthony JW, Bideaux RA, Bladh KW, Nichols MC (eds) (1990) Graphite. In: Handbook of mineralogy. I (elements, sulfides, sulfosalts). Chantilly, VA, US: Mineralogical Society of America. ISBN 978-0962209703

2. Kumar D, Arora S (2017) Evaluation of physico-chemical, thermal and mechanical properties of sintered graphite and mesophase formulations. J Mater Sci Eng 6:1

3. Marinho B, Ghislandi M, Tkalya E, Koning CE, de With G (2012) Electrical conductivity of compacts of graphene, multi-wall carbon nanotubes, carbon black, and graphite powder. Powder Technol 221:338-351

4. Sato S, Sato K, Jmamura Y (1975) Determination of the thermal shock resistance of graphite by arc discharge heating. Carbon 13(4):309-316

5. lijima S (1991) Helical microtubules of graphite carbon. Nature 354:56-58

6. Endo M, Kim YA, Hayashi T, Nishmura K, Matusita T, Miyashita K, Dresselhaus MS (2001) Vapor-grown carbon fibers (VGCFs); basic properties and their battery applications. Carbon 39(9):1287-1297

7. Hammel E, Tang X, Trampert M, Schmitt T, Mauthner K, Eder A, Pötschke $P$ (2004) Carbon nanofiber for composite applications. Carbon 42(6):1153-1158

8. Ebbesen TW, Ajayan PM (1992) Large-scale synthesis of carbon nanotubes. Nature 358:220-222
9. Guo T, Nikolaev P, Rinzler AG, Tomanek D, Colbert DT, Smalley RE (1995) Self-assembly of tubular fullerenes. J Phys Chem 99(27):10694-10697

10. Smiljanic Olivier, Stansfield BL, Dodelet J-P, Serventi A, Désilets S (2002) Gas-phase synthesis of SWNT by an atmospheric pressure plasma jet. Chem Phys Lett 356(3-4):189-193

11. Walker PL Jr, Rakszawski JF, Imperial GR (1959) Carbon formation from carbon monoxide-hydrogen mixtures over iron catalysts. I. Properties of carbon formed. J Phys Chem 63(2):133-140

12. José-Yacamán M, Miki-Yoshida M, Rendón L, Santiesteban JG (1993) Catalytic growth of carbon microtubules with fullerene structure. Appl Phys Lett 62(6):657

13. Ren Jiawen, Li Fang-Fang, Lau Jason, González-Urbina Luis, Licht Stuart (2015) One-pot synthesis of carbon nanofibers from $\mathrm{CO}_{2}$. Nano Lett 15(9):6142-6148

14. de Heer WA, Berger C (2012) Epitaxial graphene. J Phys D Appl Phys 45(15):150301-150302

15. Cao X, Yin Z, Zhang H (2014) Three-dimensional graphene materials: preparation, structures and application in supercapacitors. Energy Environ Sci 7:1850-1865

16. Cao X (2014) Metal oxide-coated three-dimensional graphene prepared by the use of metal-organic frameworks as precursors. Angew Chem 126:1428-1433

17. Kim J, Cote LJ, Huang J (2012) Two dimensional soft material: new faces of graphene oxide. Acc Chem Res 45:1356-1364

18. Hagino T, Kondo H, Ishikawa K, Kano H, Sekine M, Hori M (2012) Ultrahigh-speed synthesis of nanographene using alcohol inliquid plasma. Jpn Soc Appl Phys 5(3):035101

19. Amano $T$, Kondo $H$, Takeda $K$, Ishikawa $K$, Hiramatsu $M$, Sekine M, Hori M (2018) Nanographene synthesized in triple-phase plasmas as a highly durable support of catalysts for polymer electrolyte fuel cells. Jpn J Appl Phys 57:045101

20. Amano T, Kondo H, Ishikawa $\mathrm{K}$, Tsutsumi T, Takeda K, Hiramatsu M, Sekine M, Hori M (2018) Rapid growth of micron-sized graphene flakes using in-liquid plasma employing iron phthalocyanine-added ethanol. Appl Phys Express 11:015102

21. Ando A, Ishikawa $K$, Kondo $H$, Tsutsumi T, Takeda $K$, Ohta $T$, Ito $M$, Hiramatsu M, Sekine M, Hori M (2018) Nanographene synthesis employing in-liquid plasmas with alcohols or hydrocarbons. Jpn J Appl Phys 57:026201

22. Gui D, Liu C, Chen F, Liu L (2014) Preparation of polyaniline/graphene oxide nanocomposite for the application of supercapacitor. Appl Surf Sci 307(15):172-177

23. Li ZQ, Lu CJ, Xia ZP, Zohu Y, Luo Z (2007) X -ray diffraction patterns of graphite and turbostratic carbon. Carbon 45(8):1686-1695

24. Seung HH (2011) Thermal reduction of graphene oxide, physics and applications of graphene-experiments. InTech, ISBN 978-953-307-217-3

Publisher's Note Springer Nature remains neutral with regard to jurisdictional claims in published maps and institutional affiliations. 